DOI: https://doi.org/10.30749/2594-8261.v2n2p245-257

\title{
IGUALDADE DE PODER ENTRE HOMENS E MULHERES: REFLEXÕES A PARTIR DA AGENDA 2030 DA ONU
}

\section{EQUAL POWER BETWEEN MEN AND WOMEN: REFLECTIONS BASED ON THE AGENDA 2030 OF THE UNU}

\author{
Maria Geralda de Miranda* \\ Débora Coqui \\ Patrícia Maria Dusek \\ Katia Eliane Santos Avelar
}

Resumo: O assunto "empoderamento" da mulher tem sido bastante discutido nos últimos tempos e traz à tona questões sobre desenvolvimento e liberdade, elementos primordiais para a emancipação dos indivíduos, visando à expansão de suas capacidades. O presente trabalho faz uma reflexão sobre Objetivo número 5 , ODS nำ 5, da Agenda 2030 da Organização das Nações Unidas, ONU, ressaltando sua importância para o desenvolvimento das mulheres e, portanto, para o seu "empoderamento". Para a discussão dos tópicos constantes no ODS 5 apoiou-se em Amartya Sen, entre outros autores, a partir de sua reflexão sobre a liberdade, e em outro documento da ONU sobre os princípios do empoderamento da mulher. As conclusões apontam para a necessidade de políticas públicas e programas que devem ir além das áreas de saúde, educação e garantia de melhores condições de vida, uma vez que é necessário promover políticas para a igualdade de poder e ocupação de espaços políticos.

\footnotetext{
" Mestre em Literatura Comparada com ênfase nos estudos culturais pela Universidade Federal Fluminense (UFF) e Doutora em Letras com ênfase em estudos pós-coloniais, também pela UFF. Professora do Programa de Pós-Graduação em Desenvolvimento Local, do Centro Universitário Augusto Motta, UNISUAM.

Possui graduação em Direito. Advogada especialista em Direito do Trabalho e Previdenciário. Atua no Núcleo de Prática Jurídica da Unisuam (Centro Universitário Augusto Motta) nas áreas de Família, Trabalho, Previdenciário e Consumidor. Hoje, atua como responsável pelo projeto: Acesso À Justiça Nas Comunidades Da Mangueira E Manguinhos Como Efetivação Dos Direitos Humanos E Cidadania, na Casa do Trabalhador de Manguinhos e Faetec Mangueira. Mestranda em Desenvolvimento Local do Centro Universitário Augusto Motta.

Pós Doutora pela Universitá di Pisa (2015). Doutora em Direito pela Universidade Veiga de Almeida (2014). Mestre em Direito pela Universidade Cândido Mendes, onde também obteve o título de graduação na mesma área. Especialista em Direito pela EMERJ. Pesquisadora e membro da Comissão de Pesquisa da Universidade Castelo Branco - UCB. Parecerista ad hoc de Revistas Científicas. Professora da Universidade Castelo Branco e do Centro Universitário de Barra Mansa

Possui graduação em Farmácia e Bioquímica pela Universidade Federal de Juiz de Fora (1993), Mestrado em Ciências Biológicas pela Universidade Federal do Rio de Janeiro (UFRJ) (1996) e Doutorado em Ciências também pela Universidade Federal do Rio de Janeiro (2002). Atualmente é coordenadora do Laboratório de Referência Nacional para Leptospirose do Instituto Oswaldo Cruz (FIOCRUZ). Professora Titular e Pesquisadora do Programa de Pós-Graduação Profissional Interdisciplinar em Desenvolvimento Local do Centro Universitário Augusto Motta (UNISUAM). Pesquisadora da Universidade Santa Úrsula.
} 
Palavras-chave: Agenda 2030. Igualdade de poder. Desenvolvimento e Liberdade.

Abstract: The subject of empowerment of women has been much discussed in recent times and raises questions about development and freedom, primordial elements for the emancipation of individuals, aimed at expanding their capabilities. The present work reflects on Objective number 5, ODS no 5, of Agenda 2030 of the United Nations Organization, emphasizing its importance for the development of women and, therefore, for their empowerment. For the discussion of the topics contained in ODS 5, she supported Amartya Sen, among others, based on her reflection on freedom, and another ONU document on the principles of women's empowerment. The conclusions point to the need for public policies and programs that must go beyond the areas of health, education and guarantee of better living conditions, since it is necessary to promote policies for equality of power and occupation of political spaces.

Keywords: 2030 Agenda. Equal power. Development as Freedom. 


\section{INTRODUÇÃO}

A Agenda 2030 da Organização das Nações Unidas, ONU, firmada por chefes de Estado e de Governo e altos representantes, reunidos na sede das Nações Unidas em Nova York entre os dias 25 e 27 de setembro de 2015, no momento em que a Organização comemorava seu septuagésimo aniversário, traz novos Objetivos visando ao Desenvolvimento Sustentável global, como a erradicação da pobreza em todas as suas formas e dimensões, incluindo a pobreza extrema.

Tal Agenda, em seu Objetivo ํo 5, ODS 5, objeto deste trabalho, traça metas para alcançar a igualdade de gênero e empoderar todas as mulheres e meninas. Os tópicos de tais objetivos são os seguintes: 5.1 - acabar com todas as formas de discriminação contra todas as mulheres e meninas em toda parte; 5.2 - eliminar todas as formas de violência contra todas as mulheres e meninas nas esferas públicas e privadas, incluindo o tráfico e exploração sexual e de outros tipos; 5.3 eliminar todas as práticas nocivas, como os casamentos prematuros, forçados e de crianças e mutilações genitais femininas.

O tópico 5.4 aborda o reconhecimento e a valorização do trabalho de assistência e doméstico não remunerado, por meio da disponibilização de serviços públicos, infraestrutura e políticas de proteção social, bem como a promoção da responsabilidade compartilhada dentro do lar e da família, conforme os contextos nacionais; o tópico 5.5 prevê a garantia e a participação plena e efetiva das mulheres e a igualdade de oportunidades para a liderança em todos os níveis de tomada de decisão na vida política, econômica e pública.

Já o 5.6 assegura o acesso universal à saúde sexual e reprodutiva e os direitos reprodutivos, como acordado em conformidade com o Programa de Ação da Conferência Internacional sobre População e Desenvolvimento e com a Plataforma de Ação de Pequim e os documentos resultantes de suas conferências de revisão; ao passo que o 5.a prevê a realização de reformas para dar às mulheres direitos iguais aos recursos econômicos, bem como ao acesso à propriedade e controle sobre a terra e outras formas de propriedade, serviços financeiros, herança e aos 
recursos naturais, de acordo com as leis nacionais. O tópico 5.b foca prevê o aumento do uso de tecnologias de base, em particular as tecnologias de informação e comunicação, para promover o empoderamento das mulheres, e o 5.c assegura o fortalecimento de políticas sólidas e legislação aplicável para a promoção da igualdade de gênero e o empoderamento de todas as mulheres e meninas em todos os níveis.

\section{DESENVOLVIMENTO}

Apesar do termo empoderamento em inglês (empowerment) significar dar poder a, permitir ou também autorizar, neste trabalho será seguido o conceito do pensador brasileiro Paulo Freire e Ira Shor (1986) que está associado à ideia da libertação do sujeito oprimido e a noção de conquista da liberdade. Freire e Shor propõem outra percepção de empowerment - o empoderamento de classe social. Isso significa na compreensão desses autores que não se trata de um processo de natureza individual, mas de desenvolvimento social. Os autores afirmam não acreditarem na autolibertação; a libertação é um ato social (FREIRE; SHOR, 1986).

O sentido da expressão na língua inglesa remete a uma situação de passividade por parte do empoderado, já que, por definição, o poder the é dado por alguém. Neste sentido, Paulo Freire e Ira Shor (1986) também ensinam que o empoderamento, enquanto liberdade, não é um presente e nem está naturalmente posto. Adquire-se pela conquista e deve ser buscado constantemente. É neste sentido que deve pensar o empoderamento.

Conforme Rosana Ferrari (2013) vários são os percursos em que passa o empoderamento feminino na sociedade. O conhecimento dos direitos, a sua inclusão social, instrução, profissionalização, consciência de cidadania e, também, "por uma transformação no conceito que ela tem dela mesma, em sua autoestima" (FERRARI, 2013, p. 2).

Muitas situações marcadas na história contribuíram para o início do empoderamento feminino, como por exemplo, a criação do dia Internacional da 
Mulher, em $1911^{1}$, devido a um incêndio que matou mais de 100 operárias em na fábrica Triangle Shirtwaist, em Nova York. E, ainda, a conquista do voto feminino, em 1932, e a criação da Lei Maria da Penha (Lei no 11.340), de 2006, que recebeu o nome da farmacêutica e bioquímica Maria da Penha Maia Fernandes, uma sobrevivente, após seu marido tentar matá-la duas vezes. Só para citar exemplos de que a luta da mulher é histórica para garantir direitos, que parecem básicos como o de votar e o de não apanhar do marido.

A independência da mulher é fator altamente importante para a sua libertação e determinante para a iniciativa individual e para a eficácia social. A Agenda 2030, por meio do ODS 5, mostra-se preocupada com várias dimensões da problemática feminina, desde a valorização do trabalho doméstico, até a elaboração de políticas públicas, visando possibilitar o acesso à renda e à participação política. Todas os tópicos do ODS 5 voltam-se para o desenvolvimento do potencial da pessoa - mulher - que precisa cuidar de si mesma e participar de maneira plena dos destinos e dos rumos da comunidade como agentes de desenvolvimento e não seres de segunda categoria.

Trata-se de assegurar o direito das mulheres participarem da política, mas para tanto é necessário, para a maioria, ainda, garantir as condições de sobrevivência e independência, o que passa evidentemente pela questão da escolaridade, que ainda é um problema para meninas e mulheres. A educação, como ensina Amartya Sen (2010) é uma das capacidades fundamentais que o indivíduo precisa ter para conseguir a liberdade.

Dentro desta visão, Azevedo (2012, p. 31) também mostra que "a liberdade, vista sob a perspectiva instrumental, classifica-se em cinco tipos distintos de direitos e oportunidades, quais sejam, as liberdades políticas, as facilidades econômicas, as oportunidades sociais, as garantias de transparência e segurança protetora." Em sua maneira de ver, a educação, a profissionalização e a independência feminina podem favorecer a redução das desigualdades contra o

\footnotetext{
${ }^{1}$ O Dia Internacional da Mulher foi proposto por Clara Zetkin em 1910 no II Congresso Internacional de Mulheres Socialistas. Nos anos posteriores a 1970 este Dia passou a ser associado a um incêndio que ocorreu em Nova lorque em 1911. Neste artigo procuro recuperar a história do Dia 8 de Março e as distorções que têm sido feitas sobre ele e sobre a luta feminista. (BLAY, 2001, p. 601.)
} 
sexo feminino nas tomadas de decisões familiares, influenciando para a mudança social em geral.

Além de seu aspecto político, as liberdades substantivas implicam direitos que garantem a qualidade de vida, a segurança econômica e física, a proteção contra fomes e doenças tratáveis, mecanismos de combate a diversas formas de discriminação e transparência nas relações sociais (AZEVEDO, 2012, p. 34). Desse modo, o Estado, em sintonia com o ODS 5, deve desempenhar o seu papel, não apenas legislando, de modo a tentar coibir discriminações e abusos contra a mulher, sob ameaças de sanção, mas efetivamente, na promoção de mecanismos de conscientização, no sentido de maximizar a igualdade entre os gêneros, por meio de políticas públicas de ações afirmativas.

O tópico 5.a, do ODS 5, é claro ao prever a realização de reformas para dar às mulheres direitos iguais aos recursos econômicos, bem como ao acesso à propriedade e controle sobre a terra e outras formas de propriedade, serviços financeiros, herança e aos recursos naturais, de acordo com as leis nacionais, o que, obviamente, coloca a mulher como cidadã e agente de desenvolvimento, mas para tanto é necessária a atuação do Estado no sentido de promover políticas que venham assegurar à mulher, além de atuação política, participação no desenvolvimento econômico do país, não apenas como trabalhadoras, mas como empresárias e executivas de grandes empreendimentos.

Empoderar mulheres e promover a igualdade de gênero em todas as atividades sociais e da economia são garantias para o efetivo fortalecimento das economias, o impulsionamento dos negócios e a melhoria da qualidade de vida de todos.

Na visão de SACCHET (2008) "os altos índices de capital social também contribuem para promover equidade política entre homens e mulheres. Assim, sociedades com índices mais altos de CS teriam também maior igualdade social e política de gênero" (SACCHET, 2008, p. 5).

Em 2010, a organização das nações Unidas, mediante parceria entre a ONU Mulheres e o Pacto Global, lança os sete princípios que auxiliam no poder da mulher em relação ao meio empresarial e a comunidade - Os Princípios de Empoderamento 
das Mulheres, Women Empowerment Principles - WEPs: (ONU MULHERES, [2018?])

1. Estabelecer liderança corporativa sensível à igualdade de gênero, no mais alto nível.

2. Tratar todas as mulheres e homens de forma justa no trabalho, respeitando e apoiando os direitos humanos e a não-discriminação.

3. Garantir a saúde, segurança e bem-estar de todas as mulheres e homens que trabalham na empresa.

4. Promover educação, capacitação e desenvolvimento profissional para as mulheres.

5. Apoiar empreendedorismo de mulheres e promover políticas de empoderamento das mulheres através das cadeias de suprimentos e marketing.

6. Promover a igualdade de gênero através de iniciativas voltadas à comunidade e ao ativismo social.

7. Medir, documentar e publicar os progressos da empresa na promoção da igualdade de gênero. (ONU MULHERES, [2018?])

A intenção com tais medidas é também orientar o estabelecimento de políticas visando à regularização dos direitos da mulher na sociedade. O princípio 1은 pretende afirmar apoio e direcionar políticas para a igualdade de gênero e direitos humanos; estabelecer metas para as empresas no que tange à igualdade de gênero.

O $2^{\circ}$ princípio aborda as oportunidades e as práticas no ambiente de trabalho de modo que não haja diferenciação de remuneração, de recrutamento e nomeação para cargos de gerência e administração etc.

Já o 3ำ principio trata das condições seguras de trabalho e proteção contra a exposição a materiais perigosos, bem como da divulgação de riscos, para a saúde reprodutiva. O respeito aos direitos de trabalhadores homens e mulheres e também da necessidade de tempo livre para cuidados médicos e orientação profissional para si mesmos e seus dependentes. E, ainda, da eliminação de todas as formas de violência no trabalho, seja verbal e/ou física e também do assédio sexual.

Com relação à educação, capacitação e desenvolvimento profissional, retratados no princípio $4^{\circ}$, vizualiza-se a possibilidade das empresas investirem em políticas e programas no local de trabalho que abram caminho para a promoção das mulheres em todos os níveis e áreas de negócio, bem como estimulá-las a entrar em 
campos de trabalho que não os tradicionais. Garantir igual acesso a todos os programas de educação e treinamento.

O princípio $5^{\circ}$ foca na possibilidade de soluções sensíveis para as barreiras ao crédito e empréstimo a mulheres. E ainda no compromisso da empresa em promover a igualdade e a inclusão, respeitando a dignidade das mulheres em todos os materiais de marketing e outros da empresa.

Ao trabalhar a igualdade, o $6^{\circ}$ princípio, evidencia o compromisso da empresa com a igualdade de gênero e o empoderamento, eliminando a discriminação e a exploração, ao abrir oportunidades para mulheres.

E, por fim, o último a ser citado, o $7^{0}$ princípio, traz a questão de divulgar publicamente as políticas da empresa e plano de implementação para promover a igualdade de gênero e estabelecer marcos que quantifiquem a inclusão das mulheres em todos os níveis. Assim, deve-se medir e divulgar o progresso, tanto interna quanto externamente, usando dados desmembrados por sexo.

O Conselho Nacional dos Direitos da Criança e do Adolescente (Conanda) também aprofundou as discussões sobre a igualdade de gênero. No dia 20 de outubro de 2016, publicou a Resolução № 180, que dispõe sobre a igualdade de direitos entre meninas e meninos nas políticas públicas de atenção, proteção e defesa de crianças e adolescentes. Importante iniciativa no sentido de contribuir para a superação das situações de desigualdade e desequilíbrio que acabam por não permitir o pleno desenvolvimento das meninas, em especial, das moradoras em comunidades carentes.

Tal resolução pode ser considerada um marco, por ser o primeiro ato normativo voltado à garantia dos direitos das meninas e das adolescentes no Brasil, que até possui consideráveis dispositivos legais que visam à proteção de crianças e adolescentes, porém nenhum considerava as especificidades de gênero. Nem mesmo os dispositivos voltados para a área da mulher contemplavam as questões específicas das meninas.

O documento traz recomendações específicas no sentido de promover a igualdade de direitos e combater as discriminações contra as meninas e é direcionado para o Sistema de Garantia de Direitos (SGD), Poder Judiciário, 
Ministério Público da União, Ministério Público dos Estados, Defensoria Pública da União, Defensorias Públicas Estaduais, Advocacia Geral da União, procuradorias gerais dos estados, Polícias Civil, Militar e Federal, Ouvidorias e Conselhos Tutelares. E vai além: orienta os órgãos responsáveis pelas políticas públicas das áreas de educação, saúde, assistência social, cultura, esporte, proteção e defesa.

A Agenda 2030 vai ao encontro do pensamento de Amartya Sen (2010), que pensa o desenvolvimento humano como alargamento das liberdades e capacidades. O conceito de desenvolvimento, na visão de Sen (2010) deixa de ser visto apenas como crescimento econômico e passa a tomar características de um conceito amplo, formado por variáveis complexas, porém extremamente necessárias, como a medição da pobreza além da ausência de renda e o acesso a serviços sociais básicos como saúde e educação.

A privação de renda e recursos não-materiais que determinam a pobreza é um dos primeiros pontos a ser combatido em políticas comprometidas com a questão do desenvolvimento, mas o conceito de pobreza determinado por Sen (2010) como privação de capacidades é fundamental para as que novas propostas em torno da questão do desenvolvimento obtenham sucesso.

Para Sen (2010), liberdade é a palavra chave no processo de desenvolvimento. Seguramente, o crescimento econômico é importante para o desenvolvimento, contudo qualidade de vida, sustentabilidade ambiental, equidade e respeito cultural da população passam por um conjunto de elementos. Indicadores como o Índice de Desenvolvimento Humano, IDH, formulado pela ONU, que mensura além da pobreza, educação e esperança de vida, são importantes.

Ainda segundo Sen (2010), a liberdade individual é um produto social, existindo uma relação de mão dupla entre (1) as disposições sociais que visam expandir as liberdades individuais e (2) o uso de liberdades individuais para melhorar a vida de cada um e tornar as disposições sociais mais apropriadas e eficazes (SEN, 2010, p. 48).

A Agenda 2030 da ONU, na totalidade do seu Objetivo número 5, passa a ideia de que a sustentabilidade do Planeta Terra não se realizará sem a participação integral da mulher em todas as áreas. E que tal participação não se poderá efetivar 
se questões humanas e prioritárias não forem resolvidas como o direito da mulher à educação e à liberdade para decidir sobre seu corpo e sua vida.

O acesso das mulheres ao trabalho e, portanto, à renda é fundamental para a conquista de espaços de poder político, uma vez que a emancipação da mulher não pode ser pensada se esta for dependente economicamente, se não tiver acesso à escola. $O$ trabalho doméstico também precisa deixar de ser tratado como um não trabalho ou como um trabalho desvalorizado, uma vez que a mudança de tal estatuto contribuirá com a emancipação das mulheres que o realiza.

A Agenda 2030 também deixa claro que a não há sustentabilidade planetária com populações inteiras passando fome, o que remete a situações vivenciadas no cotidiano de cidades grandes, como o Rio de Janeiro, onde se pode observar que uma grande quantidade de mulheres pobres cuidando sozinhas de sua prole, como o que acontece com mães de comunidades em que os filhos são sempre "filhos da mãe", porque os pais os abandonaram ou estão mortos. O ODS 5 também deixa evidente que $n$ se efetiva a cidadania, a liberdade e a igualdade tão bem discutidas por Amartya Sen (2010) com as mulheres fora da escola e ganhando menos que os homens, ou sendo discriminadas e violentadas e, as vezes, mesmo mortas por companheiros ou mesmo pessoas da família.

\section{CONSIDERAÇÕES FINAIS}

O ODS n 5 da Agenda 2030 propõe intensificar as realizações no combate às discriminações e violências voltadas para a questão de gênero, buscando paralelamente o empoderamento de mulheres e meninas para que tenham maior interação com o mundo que estão inseridas, em campos como a política e economia.

Para alcançar tais objetivos, as políticas públicas devem ir muito além das áreas de saúde, educação e garantia de melhores condições de vida. É necessário promover, de fato, políticas para a igualdade de poder, e ocupação de espaços políticos. 
Como afirma Baquero (2012, p. 183-184), empoderamento, enquanto categoria, perpassa noções de democracia, direitos humanos e participação, mas não se limita a estas. Implica processos de reflexão sobre a ação, visando a uma tomada de consciência a respeito de fatores de diferentes ordens: econômica política e cultural, que conformam a realidade, incidindo sobre o sujeito. Neste sentido, um processo de empoderamento eficaz necessita envolver tanto dimensões individuais quanto coletivas.

$\mathrm{Na}$ verdade, é necessário realizar projetos, políticas e programas pensando na igualdade. Trata-se, em última instância de um processo educacional, de uma educação para a igualdade, uma vez que é comum ainda hoje ouvir que meninos devem comportar-se de determinada maneira e meninas de outra; que menina é delicada, sensível e expressa suas emoções e que menino deve ser forte, valente e não chorar; mulheres devem preservar sua imagem, sendo recatadas e caseiras e os homens devem ser aventureiros, garanhões e, a todo tempo, comprovar sua masculinidade; a mulher deve ser uma boa esposa, mãe e dona de casa e o homem deve exercer a autoridade e ser o provedor do lar.

Conforme Silva (2015) muitas dessas idealizações foram substituídas por outros paradigmas socialmente construídos e difundidos, levando-se em consideração o contexto social, econômico e cultural dos sujeitos, mas há outras representações do que é ser homem e mulher que, por sua força ideológica, tornamse seculares e ocasionam desigualdades entre os sexos que ultrapassam questões biológicas e atingem esferas sociais, econômicas e políticas.

Em razão disso, a Agenda 2030, especialmente o ODS 5, é muito oportuno e fundamental para a realização de mudanças na sociedade, visando à igualdade e a liberdade das pessoas. Como diz a escritora Adélia Prado (2018) "não parece existir um condição feminina anterior a minha condição humana. A experiência da opressão é vivenciada sempre como um ultraje à dignidade humana e não á dignidade feminina ou masculina."

Como se infere a partir de Adélia Prado, a superação da desigualdade entre homens e mulheres é uma necessidade humana para a completude de sua dignidade. 


\section{REFERÊNCIAS}

AZEVEDO, Vilma Maria. Os desafios para o empoderamento da mulher agricultora a partir do programa de aquisição de alimentos: o caso de Barbacena-MG. 2012. 195 f. Dissertação (Mestrado) - Universidade Federal de Viçosa, Viçosa, MG, 2012. Disponível em: <http://locus.ufv.br/bitstream/handle/12345678 9/4179/texto\%20completo.pdf?sequence=1\&i sAllowed=y>. Acesso: 04 mar. 2018.

BAQUERO, Rute Vivian Angelo. Empoderamento: instrumento de emancipação social?: uma discussão conceitual. Revista Debates, Porto Alegre, v. 6, n. 1, p.173187, jan./abr. 2012.

BLAY, Eva Alterman. 8 de março: 8 de março: conquistas e controvérsias. Estudos feministas, Florianópolis, v. 9, n. 2, p. 601-607, 2001. Disponível em: $<$ https://periodicos.ufsc.br/index.php/ref/article/view/S0104026X2001000200016/8870 >. Acesso: 23 ago. 2018.

FERRARI, Rosana. O Empoderamento da Mulher. Instituto de Terapia e Centro de Estudo da Família, Curitiba, artigos, [2013]. Disponível em: <http://www.fap.sc.gov.br/noticias/empoderamento.pdf>. Acesso em: 20 mar. 2018.

FREIRE, Paulo; SHOR, Ira. Medo e ousadia: o cotidiano do professor. Rio de Janeiro: Paz e Terra, 1986.

ONU. Transformando nosso mundo: a Agenda 2030 para o desenvolvimento sustentável. 2018. Disponível em: <https://nacoesunidas.org/pos2015/agenda2030/>. Acesso em: 29 ago. 2018.

ONU MULHERES. Princípios de empoderamento das Mulheres. [2018?]. Disponível em: <http://www.onumulheres.org.br>. Acesso em: 20 jun. 2018.

PRADO, Adélia. Por um feminismo sem azedume (com mais doçura). 2018. Disponível em: <http://vivendonobliterado.blogspot.com/2018/02/por-um-feminismosem-azedume-com-mais.html>. Acesso: 23 ago. 2018.

SACCHET, Teresa. Capital social, gênero e representação política no Brasil. Opinião Pública, v. 15, n. 2. Campinas, p. 306-332, nov. 2009. Disponível em: $<$ http://www.scielo.br/scielo.php?script=sci_arttext\&pid=S010462762009000200002>. Acesso em: 21 abr. 2018.

SEN, Amartya. Desenvolvimento como liberdade. São Paulo: Companhia das Letras, 2010. 
SILVA, AD. Ser homem, ser mulher: as reflexões acerca do entendimento de gênero. In: Mãe/mulher atrás das grades: a realidade imposta pelo cárcere à família monoparental feminina. São Paulo: Cultura Acadêmica, 2015. p. 51-100. Disponível em: <http://books.scielo.org>. Acesso: 23 ago. 2018. 